\title{
LA COMUNICACIÓN DE LAS ONGD: LA LENTA EROSIÓN DEL ENFOQUE CARITATIVO DOMINANTE
}

\section{NGDOs Communication: The Slow Erosion of Dominant Charitable Approach}

\section{A comunicação das ONGD: a lenta erosão do enfoque caritativo dominante}

Iranzo, Amador. Universitat Jaume I de Castellón (España)

iranzo@uji.es

Fecha de recibido: 1 de junio de 2016

Fecha de aceptado: 30 de junio de 2016

\section{RESUMEN}

Desde hace años, el sector de las ONGD está sometido a un intenso debate sobre su forma de trabajar. Una de las críticas más extendidas es que estas organizaciones, en especial las de mayores dimensiones, favorecen con su comunicación una solidaridad de consumo que desincentiva la transformación social. El presente artículo presenta parte de los resultados de un proyecto europeo que estudió las prácticas comunicativas y los discursos de las ONGD de Cataluña, España, en concreto, de los sitios web de diecisiete organizaciones. Los hallazgos muestran una lenta erosión del enfoque hegemónico en las ONGD basado en los estereotipos Norte-Sur, que centra su comunicación en la captación de donaciones. Frente a esta visión, la mayoría de las ONGD analizadas (diez de diecisiete) muestran una orientación dominante, en mayor o menor grado, hacia un enfoque comunicativo alternativo que persigue el cambio social. De todas formas, el discurso hegemónico sigue prevaleciendo en las organizaciones de mayores dimensiones y visibilidad.

Palabras clave: ONGD, comunicación, sitios web, cooperación internacional. 


\section{ABSTRACT}

The NGDOs sector is subjected for years to an intense debate about the way they work. One of the most widespread criticisms is that these organizations, especially the larger ones, use a communication style that favors a consumer solidarity that discourages social transformation. This article presents part of the results of a European project that studied the communicative practices and discourses of NGDOs of Catalonia (Spain), namely, analysis of the websites of 17 organizations. The results show a slow erosion of the hegemonic approach in NGDOs based in the North-South stereotypes, which focuses its communication on attracting donations. Faced with this vision, most of the NGDOs analyzed (10 of 17) show a dominant orientation, to a greater or lesser degree, to an alternative communicative approach that pursues social change. However, the hegemonic discourse remains prevalent in larger and more visible organizations.

Keywords: NGDOs,communication, websites, international cooperation.

\section{RESUMO}

O setor das ONGD está submetido desde há anos a um intenso debate sobre a sua forma de trabalhar. Uma das críticas mais estendidas é que estas organizações. Especialmente as de maiores dimensões, favorecem com a sua comunicação uma solidariedade de consumo que desincentiva a transformação social. O presente artigo apresenta parte dos resultados de um projeto europeu que estudou as práticas comunicativas e os discursos das ONGD de Catalunha (Espanha), em concreto, a análise dos sites de 17 organizações. Os resultados mostram uma lenta erosão do enfoque hegemónico nas ONGD, baseado nos estereótipos Norte-Sul, que centra a sua comunicação na captação de doações. Frente a esta visão, a maioria das ONGD analisadas (10 de 17) mostram uma orientação dominante, em maior ou menor grau, a um enfoque comunicativo alternativo que persegue a mudança sócia. De todas formas, o discurso hegemónico segue prevalecendo nas organizações de maiores dimensões e visibilidade.

Palavras-chave: ONGD, Comunicação, Sites, Cooperação internacional

\section{Introducción}

Las organizaciones no gubernamentales (ONG) y, en especial, las enfocadas al desarrollo (ONGD), están inmersas desde hace años en un intenso debate sobre su forma de trabajar y comunicar: ¿Contribuyen al cambio social o actúan como agentes legitimadores del neoliberalismo?, ¿qué impacto real tienen sus proyectos en los países empobrecidos?, ¿sirve su comunicación para activar a la ciudadanía de los países del Norte en la lucha por la 


\section{DISERTACIONES}

ESTUDIOS

Anuario electrónico de estudios en Comunicación Social

ISSN: $1856-9536$

Doi: dx.doi.org/10.12804/revistas.urosario.edu.co/disertaciones/a.4910

Volumen 10, Número 1 / Enero-junio 2017

Versión PDF para imprimir desde

http://revistas.urosario.edu.co/index.php/disertaciones

justicia social o solo para sumar donantes satisfechos que piensan que con su aportación económica están contribuyendo a cambiar el mundo?

En el marco de estos debates se planteó el proyecto europeo "Red de periodistas y comunicadores para la cooperación y el desarrollo", liderado por la Federación Catalana de ONG para la Paz, los Derechos Humanos y el Desarrollo (FCONG), y en el que también tomaron parte la Red Ródano-Alpes de Apoyo a la Cooperación (Resacoop, Francia) y el Consorcio de ONG del Piamonte (COP, Italia).

Dentro de este proyecto, que se ha desarrollado entre 2013 y 2016, se hicieron dos investigaciones en Cataluña: una que analizó el discurso - de forma específica, el referido a la cooperación y la solidaridad internacionales-y las prácticas comunicativas de las ONGD integradas en la FCONG y otra que estudió la representación de la cooperación y la solidaridad internacionales en los medios de comunicación (Giró, Farrera y Giró, 2015).

Las investigaciones realizadas en Cataluña toman como referencia teórica el trabajo de Darnton y Kirk (2011) sobre las ONGD británicas. Este estudio constató el dominio de un paradigma caracterizado por la relación entre un donante poderoso y un receptor agradecido, que explica la pobreza por los problemas internos de los países que la sufren y apela a un compromiso público de baja implicación que consigue incrementar las donaciones, pero no la calidad de ese compromiso. Frente a este paradigma, los autores defienden uno alternativo interesado en un auténtico proceso transformador orientado al cambio social, consciente de que las ayudas económicas no sirven como solución a largo plazo y que busca un compromiso profundo de la ciudadanía.

Este artículo presenta una parte de la investigación sobre las ONGD catalanas, en concreto, un análisis que busca determinar el marco (Lakoff, 2004) asociado con los dos paradigmas antes mencionados (hegemónico-caritativo o alternativo-transformador) que domina en los sitios web de diecisiete organizaciones integradas en la FCONG (hoy, Lafede.cat-Organizaciones para la Justicia Global). Los resultados apuntan a una lenta erosión del marco hegemónico de carácter caritativo: si bien es cierto que el alternativo prevalece en un mayor número de organizaciones (diez de las diecisiete), el hegemónico continúa teniendo una mayor visibilidad, porque domina o tiene un peso importante en las ONGD de mayor tamaño y, por tanto, con más impacto en la opinión pública.

\section{Estado de la cuestión}

En un mundo en crisis, cuyas instituciones están sometidas a un descrédito generalizado ${ }^{1}$, las ONG -en particular, las ONGD - se sitúan como las instituciones mejor valoradas en España (Coordinadora de ONG para el Desarrollo-España, 2010), un hecho paradójico, en el sentido de que se trata de una legitimidad de la que estas organizaciones gozan por su mera condición (entidades sin ánimo de lucro dedicadas a hacer el bien), sin necesidad de demostrar nada (Martínez Osés, 2011).

Aunque no se trata de un fenómeno nuevo - se pueden encontrar antecedentes en el siglo XIX e, incluso, con anterioridad-, las ONG experimentaron un crecimiento exponencial durante las últimas décadas del siglo XX,

1 Solo tres instituciones (de un total de dieciséis, entre las que no se encuentran las ONG) obtienen un aprobado en confianza por parte de los españoles. Las tres están vinculadas al ámbito de la seguridad y la defensa: la Guardia Civil $(6,02)$, la Policía $(5,95)$ y las Fuerzas Armadas (5,51) (Centro de Investigaciones Sociológicas, 2015). 


\section{DISERTACIONES}

ESTUDIOS

Anuario electrónico de estudios en Comunicación Social

ISSN: $1856-9536$

Doi: dx.doi.org/10.12804/revistas.urosario.edu.co/disertaciones/a.4910

Volumen 10, Número 1 / Enero-junio 2017

Versión PDF para imprimir desde

http://revistas.urosario.edu.co/index.php/disertaciones

de la mano del avance de la globalización (Gómez Gil, 2004). Sin desestimar las explicaciones que fundamentan el nacimiento de estas organizaciones en la existencia de una sociedad civil concienciada, no se puede obviar la forma en la que, en el marco de la globalización, organismos internacionales, Estados y otros actores han creado, por un lado, las oportunidades políticas necesarias (acceso a recursos y a foros de toma de decisión) para su crecimiento y, por otro, las han promovido como socias necesarias en países del Sur y en transición (Reimann, 2006).

La expansión de las ONG se ha producido, por lo tanto, en un contexto determinado que ha marcado su forma de actuar. En un momento de difusión de las políticas neoliberales, las organizaciones no gubernamentales han sido utilizadas para cubrir las carencias que dejaban los Estados en proceso de retirada, como proveedores baratos de servicios anteriormente en manos públicas o como complemento a las políticas de ajuste. Las implicaciones de este hecho son varias. Por una parte, las ONG han contribuido a legitimar, siquiera de forma involuntaria, las nuevas doctrinas liberales (Gómez Gil, 2004), al validar con su actuación el papel de la iniciativa privada y el discurso de la incapacidad del Estado para cubrir las necesidades sociales (Serrano Oñate, 2002). Además, estas entidades se han dejado atrapar por el "espíritu de empresa" (Sogge y Zadek, 1998, p. 105), por la lógica mercantil (Nieto, 2002) y han asumido unos valores y formas de actuar -competencia, eficiencia en el corto plazo, crecimiento...-alejados de los que, en teoría, deberían regir en unas organizaciones que luchan por la transformación y la justicia social.

De esta forma, el mundo de las ONG se ha convertido en un "mercado de la solidaridad" (Ballesteros García, 2002, p. 89), en el que las organizaciones compiten por conseguir los máximos recursos de sus potenciales donantes con mensajes emotivos o simplistas que pueden ser efectivos para captar fondos, pero que resultan contraproducentes para el objetivo de conseguir cambios estructurales. Se ha instalado, así, el mito de la "comodidad de la solidaridad" (Ballesteros García, 2002, p. 90), según el cual ser solidario es una tarea fácil que no exige ningún esfuerzo y que se puede cumplir cuando das lo que te sobra o no necesitas.

La labor de las ONG, en general, y el impacto de su actuación en los países empobrecidos, en particular, empezaron a ser cuestionados tanto desde la academia como desde las propias organizaciones, en especial, a partir de la década del noventa del siglo pasado (Centre Tricontinental, 1998; Clark, 1991; Hulme y Edwards, 1997). En España, el debate, algo posterior, no fue menos intenso, hasta el punto de que algunos investigadores han llegado a hablar de anticooperación (Llistar, 2009). En mayo de 2011, la Plataforma 2015 y Más, integrada por once ONGD que se definen como progresistas, organizó unas jornadas con el objetivo de analizar la capacidad de transformación actual de estas organizaciones. La conclusión apuntaba a que las ONGD españolas se habían "desnaturalizado", es decir, se habían alejado de sus orígenes (Plataforma 2015 y Más, 2011). La desvinculación entre prácticas y principios había provocado una "pérdida de la perspectiva estratégica de su acción por la interiorización, en numerosas ocasiones de manera inconsciente, de una perspectiva eminentemente técnica o incluso instrumental de los proyectos y acciones" (Plataforma 2015 y Más, 2011, p. 79).

Las críticas al funcionamiento de las ONGD españolas coincidían en señalar sus principales males: incapacidad para ampliar y movilizar su base social, burocratización, falta de independencia, pérdida de capacidad crítica y de transformación y preocupación excesiva por las tareas de captación y gestión de recursos (Gómez Gil, 2005; 2013; Martínez Osés, 2011; Ruiz-Giménez, 2013). Frente a esta situación, se hace necesaria una "recuperación de la política y una no gubernamentalidad efectiva" (Rizzardini, 2002, p. 335), para la que los movimientos sociales 


\section{DISERTACIONES}

ESTUDIOS

Anuario electrónico de estudios en Comunicación Social

ISSN: $1856-9536$

Doi: dx.doi.org/10.12804/revistas.urosario.edu.co/disertaciones/a.4910

Volumen 10, Número 1 / Enero-junio 2017

Versión PDF para imprimir desde

http://revistas.urosario.edu.co/index.php/disertaciones

pueden constituir un buen referente (Nos, Iranzo y Farné, 2012), así como un compromiso con la comunicación para el cambio social (Nos-Aldás y Santolino, 2015).

La revisión del funcionamiento de las ONGD alcanzó a su forma de comunicarse. Entre los dos modelos de comunicación que se pueden distinguir (Erro Sala, 2002), la mayoría de las organizaciones -o las más grandesoptaron por el propagandístico, de cariz marcadamente técnico, con el objetivo de poder competir con garantías en el "supermercado de la solidaridad" (Ballesteros García, 2002, p. 89). Los especialistas de la mercadotecnia impusieron su criterio y la visión más democrática-participativa de la comunicación quedó arrinconada. A cambio de obtener buenos resultados en el corto plazo, las consecuencias en el largo han sido muy graves: desmovilización de la ciudadanía -educada en el consumo de la solidaridad y no en el compromiso activo- y difusión de unos discursos legitimadores de la supremacía cultural del Norte sobre el Sur (Ballesteros García, 2002; Nos-Aldás, 2007; 2010; Santolino, 2010). En definitiva, los discursos dominantes en las ONGD transmiten, en muchas ocasiones, unas ideas que van en contra de las aspiraciones de transformación social.

La conclusión que se puede extraer es que las ONGD tienen un problema en el ámbito de la comunicación, sí, pero no técnico, sino de índole cultural, vinculado al modelo de cooperación dominante. Para superarlo, se precisa una nueva "mirada comunicacional" que integre lo comunicativo, lo educativo y lo cultural (Erro Sala, 2010, p. 137-138). Nos-Aldás $(2007 ; 2010)$ destaca la importancia de que los discursos que utilizan las ONGD en tareas de gestión (captación de fondos o voluntarios, visibilidad de marca, explicación de sus proyectos, etc.) sean culturalmente eficientes y no actúen en contra de sus mensajes de sensibilización orientados al cambio social. Esta exigencia está todavía más justificada si se tiene en cuenta que hay investigaciones que han demostrado que el uso de modelos alternativos de comunicación no afecta la recaudación de fondos para las ONGD (Pinazo y Nos-Aldás, 2016). En definitiva, las ONGD tendrían que "reinventarse como agentes de comunicación para el cambio social" (Santolino, 2010, p. 238) mediante la constitución de un "auténtico discurso alternativo global" (Rizzardini, 2002, p. 345). En la tarea de impulsar el cambio social (Marí-Sáez y Ceballos-Castro, 2015; Tufte, 2015), las redes sociales pueden desempeñar un papel fundamental para facilitar la conexión de las organizaciones con sus audiencias, aunque se trata de una herramienta todavía no muy aprovechada (Iranzo y Farné, 2014).

\section{Metodología}

El presente artículo analiza los sitios web de diecisiete ONGD integradas en la FCONG, entidad que ha pasado a llamarse Lafede.cat-Organizaciones para la Justicia Global. La muestra se eligió con varios criterios. En primer lugar, las ONGD tenían que haber formado parte de la Comisión de Comunicación de la FCONG durante el período en el que se recogieron los materiales para el conjunto de la investigación (julio de 2012-junio de 2013).

Una vez cumplido este requisito inicial, se hizo una selección representativa del conjunto de las ONGD integradas en la FCONG, de acuerdo con variables como tamaño, ámbito de trabajo o cantidad de personal dedicado a tareas de comunicación. En este proceso se contó con el asesoramiento de la Secretaría Técnica de la FCONG. La selección final estaba integrada por dieciocho entidades: Acción contra el Hambre (ACH), Acsur-Las Segovias, AlterNativa, Asamblea de Cooperación por la Paz-Cataluña (ACPP), Banco de Recursos (BdR), Centro de Estudios Africanos (CEA), Cruz Roja Cataluña (CRC), Edualter, Medicus Mundi Cataluña (MMC), Movimiento por la paz (MPDL), Observatorio de la Deuda en la Globalización (ODG), Oxfam-Intermón (OI), Proide, Servicio Civil Internacional-Cataluña (SCI-C), Setem-Cataluña, 
Sonrisas de Bombay (SdB), Unicef y Veterinarios sin Fronteras-Justicia Alimentaria Global (VSF-JAG). Aunque la muestra inicial era de dieciocho entidades, el análisis de las herramientas de comunicación de Unicef no se pudo completar por falta de información que debía facilitar esta organización.

En el análisis de los sitios web, se tuvo en cuenta, en especial, el contenido de las secciones "Quiénes somos" y "Qué hacemos" o equivalentes. En el primer caso, por ejemplo, se prestó atención a la explicación de la misión, la visión y los valores de la organización y en el segundo, al tipo y a la descripción de los proyectos en los que participa la entidad. El objetivo del análisis era determinar a cuál de los dos marcos definidos en la investigación (el hegemónico de carácter caritativo y el alternativo basado en la transformación a largo plazo y la justicia social) remitía la web de cada organización. Para facilitar el análisis, se elaboraron unos descriptores para cada uno de los marcos con base en tanto el trabajo de Darnton y Kirk (2011) como en el Código ético y de conducta de la Federación Catalana de ONG para el Desarrollo (FCONGD) aprobado en 1997 y actualizado en 2007 (FCONGD, 2007). Los principales descriptores aparecen recogidos en la tabla 1.

Tabla 1. Principales descriptores de los marcos hegemónico y alternativo

\begin{tabular}{|c|c|}
\hline Marco hegemónico caritativo & Marco alternativo transformador \\
\hline $\begin{array}{l}\text { La principal responsabilidad del proceso de desarrollo en } \\
\text { el Sur (entendido desde el punto de vista de crecimiento } \\
\text { económico) se otorga a los países del Norte. }\end{array}$ & $\begin{array}{l}\text { La principal responsabilidad de todo el proceso de } \\
\text { desarrollo (entendido no solo desde el punto de visto } \\
\text { económico) se otorga a la propia sociedad concernida. } \\
\text { Cualquier intervención externa ha de respetar este principio. }\end{array}$ \\
\hline El Norte asume un papel activo y el Sur uno pasivo. & El Sur tiene un papel activo tanto como el Norte. \\
\hline Se actúa desde una visión a corto plazo. & Se persiguen cambios y transformaciones a medio y largo plazo. \\
\hline $\begin{array}{l}\text { La relación Norte-Sur no se considera desde una perspectiva } \\
\text { de equilibrio y respeto mutuo, sino desde la superioridad } \\
\text { del Norte. }\end{array}$ & $\begin{array}{l}\text { La cooperación se considera como una relación y un } \\
\text { diálogo, basados en la mutua experiencia y en formas de } \\
\text { relación de cada una de las partes implicadas. }\end{array}$ \\
\hline $\begin{array}{l}\text { Se oculta la responsabilidad de los países y las instituciones } \\
\text { del Norte en la situación de los países del Sur. }\end{array}$ & $\begin{array}{l}\text { Se hace visible la responsabilidad del Norte en la situación } \\
\text { de los países del Sur: deuda externa, explotación de } \\
\text { recursos naturales, etc. }\end{array}$ \\
\hline $\begin{array}{l}\text { No se explican todas las causas externas e internas de las } \\
\text { realidades del Sur a las que se alude. }\end{array}$ & $\begin{array}{l}\text { Se explican todas las causas externas e internas de las } \\
\text { realidades del Sur a las que se alude como paso hacia la } \\
\text { transformación. }\end{array}$ \\
\hline $\begin{array}{l}\text { Las acciones de las ONGD están dirigidas a la consecución } \\
\text { de objetivos cuantificables. }\end{array}$ & $\begin{array}{l}\text { En el Norte, las ONGD ejecutan actividades orientadas a } \\
\text { provocar cambios en sus propios países con el objetivo de } \\
\text { transformar las relaciones Norte-Sur. }\end{array}$ \\
\hline $\begin{array}{l}\text { La solidaridad se trata como un objeto de consumo } \\
\text { accesible y fácil de conseguir que requiere una baja } \\
\text { implicación por parte de la ciudadanía (solo pagar). }\end{array}$ & $\begin{array}{l}\text { Las ONGD promueven una solidaridad basada en el } \\
\text { compromiso a largo plazo. }\end{array}$ \\
\hline $\begin{array}{l}\text { Las acciones de las ONGD tienen un fuerte componente } \\
\text { de autolegitimación. La autopresentación como actores } \\
\text { técnicamente cualificados y necesarios para resolver los } \\
\text { problemas de los países del Sur prima sobre la explicación } \\
\text { de esos problemas. La realidad y las voces del Sur quedan } \\
\text { invisibilizadas. }\end{array}$ & $\begin{array}{l}\text { Las ONGD sitúan en el centro de su comunicación la realidad } \\
\text { de los países del Sur y no a ellas mismas. El Sur aparece } \\
\text { representado con su propia voz y no por intermediarios. }\end{array}$ \\
\hline
\end{tabular}

Fuente: elaboración propia con base en Darnton y Kirk (2011) y en el Código ético y de conducta

(FCONGD, 2007). 


\section{DISERTACIONES}

ESTUDIOS

Anuario electrónico de estudios en Comunicación Social

ISSN: 1856-9536

Doi: dx.doi.org/10.12804/revistas.urosario.edu.co/disertaciones/a.4910

Volumen 10, Número 1 / Enero-junio 2017

Versión PDF para imprimir desde

http://revistas.urosario.edu.co/index.php/disertaciones

Los sitios web se analizaron entre agosto y diciembre de 2013. Siempre que fue posible, el estudio tomó en consideración las secciones y los materiales referidos de forma específica a Cataluña o las versiones de las webs en catalán.

\section{Resultados}

De acuerdo con el análisis de sus sitios web, diez de las diecisiete ONGD analizadas muestran una orientación, en mayor o menor medida, hacia el marco alternativo de transformación. El dominio de ese enfoque alternativo de la solidaridad es incluso mayor si solo se consideran las secciones de los sitios web en donde las entidades se presentan ante la ciudadanía ("Quiénes somos", "Misión, visión y valores" y otras similares). En esos apartados, aun algunas de las ONGD en las que el marco hegemónico de corte caritativo tiene un significativo peso presentan rasgos de un discurso orientado a la transformación social. Así, MMC (2013a) destaca entre sus objetivos "promover una distribución más solidaria de la riqueza y una más amplia justicia social”2; OI (2013a) se plantea como fin "erradicar la injusticia y la pobreza" y subraya la necesidad de "conseguir un cambio de valores", y Sonrisas de Bombay (2013b) apuesta por promover "una transformación hacia una sociedad más justa".

Un número muy reducido de ONGD va más allá de incluir en sus textos de presentación estas apelaciones generales a la justicia social, la solidaridad o al cambio de valores y rechaza de forma explícita el discurso caritativo hegemónico. Un buen ejemplo lo aporta Acsur-Las Segovias (2013): "Entendemos la solidaridad como una relación entre iguales, no entre 'donantes' y 'beneficiarios”. Pero la impugnación más clara del marco caritativo la proporciona Setem (2013a), en cuya web se puede leer un ataque directo al discurso hegemónico en las ONGD:

Si crees que tenemos que "ayudar" a los pobres, no somos tu ONG. Si crees que enviando alimentos y haciendo puentes les arreglamos la vida, no somos tu ONG. Si crees que lo que necesitan es nuestro dinero para llevar una vida digna, no somos tu ONG. Pero si crees que podemos cambiar las reglas del juego para que tengan la oportunidad de desarrollar su propia existencia de la manera que quieran, entonces sí que somos tu ONG.

Son escasas las organizaciones que sitúan el énfasis en el enfoque hegemónico de cariz asistencial para presentarse en sus sitios web. ACH (2013) es una de ellas: "Nuestra misión es salvar vidas eliminando el hambre a través de la prevención, la detección y el tratamiento de la malnutrición". Las acciones para acabar con el hambre se presentan como un esfuerzo del Norte (en este caso, representado por la propia entidad), mientras en el Sur, la población receptora de la ayuda asume un papel pasivo. Además, el hambre en el mundo aparece representada como un problema que se puede resolver con los conocimientos técnicos adecuados. Conviene subrayar que, incluso en organizaciones como $\mathrm{ACH}$, en las que domina el discurso asistencial, se pueden encontrar elementos del marco alternativo. Por ejemplo, esta ONGD destaca que "el hambre no es producto del azar ni de la fatalidad sino de la injusticia" (ACH, 2013), aunque no se profundiza en las causas de este orden social injusto y la solución que se ofrece no es un cambio estructural del sistema que provoca esas desigualdades, sino combatir el hambre "con programas de nutrición y salud, agua y saneamiento y seguridad alimentaria" (ACH, 2013).

2 Traducción propia. Los textos que aparecen en los sitios webs analizados estaban escritos tanto en castellano como en catalán. Para facilitar la lectura, los que estaban en catalán se han traducido al castellano. 


\section{DISERTACIONES}

ESTUDIOS

Anuario electrónico de estudios en Comunicación Social

ISSN: $1856-9536$

Doi: dx.doi.org/10.12804/revistas.urosario.edu.co/disertaciones/a.4910

Volumen 10, Número 1 / Enero-junio 2017

Versión PDF para imprimir desde

http://revistas.urosario.edu.co/index.php/disertaciones

El discurso que utilizan las organizaciones para presentarse no siempre es coherente con las actividades que realizan. Esta situación se produce sobre todo en las entidades con un planteamiento teórico próximo al marco alternativo de justicia, en las que dominan los proyectos de cooperación sobre los de incidencia y sensibilización orientados al cambio estructural. Por ejemplo, MMC (2013b) se plantea conseguir "la transformación social y un nuevo sistema de valores", pero su trabajo se enfoca en proyectos de desarrollo (por ejemplo, programas de capacitación y salud en Mozambique o de derechos sexuales y reproductivos en Ecuador), a los que dedica un $84 \%$ de los fondos recaudados. Aunque su sitio web tiene la sección "Educación y sensibilización", en la que la organización apuesta por un "cambio en los actuales modelos de propiedad privada, producción, distribución y consumo", en los últimos años, el grueso de las actividades incluidas en ese apartado (cursos de medicina tropical, jornadas sobre salud en Mozambique, etc.) parece tener poca incidencia en el logro de ese objetivo. Un caso similar es el ACPP. El planteamiento que hace esta entidad en su presentación se encuadra dentro del marco alternativo, ya que se presenta como "defensora de los valores democráticos desde una opción de justicia social y económica" (ACPP, 2013). Además, declara de forma explícita estar en contra del "asistencialismo" y apostar por un desarrollo en el que los beneficiarios sean el motor del cambio. Sin embargo, al hablar de su trabajo, dedica más atención a explicar sus proyectos de cooperación que los de educación o sensibilización. Asimismo, la explicación de los proyectos de cooperación está centrada en destacar el papel de la propia organización más que en dar protagonismo a las poblaciones locales, que no tienen voz propia. De hecho, aunque se citan las contrapartes, apenas se aportan datos sobre su trabajo.

En esta línea, el caso de OI resulta especialmente interesante. El discurso que se puede hallar en las páginas de su sitio web incluidas en la sección "Presentación" está orientado al marco alternativo -al exponer la visión de la organización, se plantean, por ejemplo, "contribuir de forma significativa al movimiento global por la justicia social" (OI, 2013b) -. Sin embargo, al explicar su actividad, prioriza los programas de desarrollo y ayuda humanitaria sobre los de sensibilización, no solo desde el punto de vista cuantitativo -Ol asegura impulsar 94 programas de desarrollo que incluyen 504 proyectos en todo el mundo, frente a las mucho más limitadas iniciativas que pueden tener un efecto más directo en conseguir cambios estructurales a largo plazo-, sino también del discursivo: el orden de las pestañas del menú de la sección "Qué hacemos" ("Programas de desarrollo", "Acción humanitaria”, "Comercio justo" y "Campañas y educación"), dispuesto de forma horizontal en la parte superior de la página, relega al último lugar, de acuerdo con el orden de lectura occidental, el trabajo más directamente vinculado con el cambio social. De todas formas, la contradicción más evidente del planteamiento de esta ONGD en defensa de la "justicia social" procede de los numerosos mensajes orientados a la captación de fondos, una característica central del marco hegemónico asistencial. El menú principal del sitio web, presente en todas sus páginas, destaca en la esquina superior derecha, con un color llamativo (naranja, frente a los dominantes verde y negro) una pestaña con el título "Haz un donativo". Además, en varias páginas aparecen mensajes adicionales que apremian al lector a hacerse socio o a entregar alguna cantidad de dinero, complementados con textos que intentan mostrar los resultados que se podrán conseguir con esa aportación.

Son muy escasas las organizaciones que mantienen una coherencia absoluta - o casi- entre sus planteamientos dentro del marco alternativo de justicia y los proyectos que desarrollan. Setem, fiel a su filosofía, no tiene proyectos de cooperación en el Sur y dedica su trabajo a diversas iniciativas y campañas en el campo de la sensibilización, formación e incidencia. VSF-JAG (2013a) también dedica su trabajo a campañas de denuncia, educación y defensa de un "cambio 


\section{DISERTACIONES}

ESTUDIOS

Anuario electrónico de estudios en Comunicación Social

ISSN: $1856-9536$

Doi: dx.doi.org/10.12804/revistas.urosario.edu.co/disertaciones/a.4910

Volumen 10, Número 1 / Enero-junio 2017

Versión PDF para imprimir desde

http://revistas.urosario.edu.co/index.php/disertaciones

de paradigma económico, político y social". En su sección "Campañas", se puede leer: "En VSF creemos en el poder del activismo y de la sociedad civil organizada para incidir en las políticas públicas para poner freno a la agroindustria y defender la Soberanía Alimentaria". Una de las campañas de VSF-JAG es "Banca bajo control", con la que la organización asegura vigilar y poner en conocimiento de las personas "las actividades de los especuladores financieros en los mercados alimentarios".

También dedicado en exclusiva a tareas de incidencia se encuentra un grupo de ONGD con características especiales: Edualter, CEA y ODG. Edualter (2013) ofrece en su web recursos pedagógicos e información para trabajar temas de educación para el desarrollo, todo ello con el objetivo de "seguir llevando adelante el compromiso con una educación transformadora hacia un mundo más justo"; CEA, una asociación dedicada al estudio y la divulgación sobre África, orienta sus actividades en esta línea de sensibilización y formación, mientras ODG (2013), como centro de investigación, persigue con sus estudios "revertir los mecanismos que perpetúan el empobrecimiento en los países del Sur y los desequilibrios Norte-Sur".

En el extremo opuesto, las organizaciones con una orientación más clara hacia el marco hegemónico caritativo desarrollan proyectos de carácter asistencial, principalmente. Es el caso de CRC (2013), que tiene en "la actuación en materia de primeros auxilios" una de sus "señas de identidad"; BdR, dedicada a la recogida y envío de material a países del Sur; $\mathrm{ACH}$, con sus actividades en los terrenos de nutrición, agua y saneamiento y salud, entre otros, y $\mathrm{SdB}$, con sus programas educativos, de salud y ocupación. De todas formas, en estas organizaciones también se pueden encontrar proyectos que, con un protagonismo muy inferior, proponen cambios estructurales a largo plazo que podrían caber en el marco alternativo de justicia. Por ejemplo, Sonrisas de Bombay (2013b) actúa también en el terreno de la sensibilización desde la creencia de que "explicar y denunciar las situaciones de vulneraciones de derechos es el primer paso para combatirlas". En este campo, la organización gestiona Mumbai Action, una agencia de noticias digital que recoge denuncias, propuestas y acciones relacionadas con la defensa de los derechos humanos procedentes de las ONG de esa ciudad. ACH (2013), en su área de incidencia política y social, destaca que abordar las causas estructurales que provocan el hambre requiere decisiones políticas. En esta línea se encuentra el Hunger Watch, un observatorio del hambre que coordina la matriz internacional de la organización.

La cuantificación del trabajo (personas atendidas, personal contratado, proyectos realizados) es visible en la información que las ONGD más cercanas al marco asistencial hegemónico facilitan en sus sitios web. Por citar algunos ejemplos, $\mathrm{ACH}$ recalca sus 300 cooperantes y 4.600 trabajadores locales que combaten el hambre; CRC desglosa en porcentajes las actividades (sobre todo, de carácter asistencial) a las que dedica las donaciones recibidas; OI informa que tiene programas en 41 países y apoya a 113 grupos de productores de comercio justo; MMC explica los fondos destinados a cada país en donde actúa, y BdR detalla los proyectos de desarrollo que promueve en el Sur, sus beneficiarios, el número de contenedores de ayuda enviados y el valor de ese material, etc. Esta preocupación por las cifras disminuye a medida que las ONGD se acercan al marco alternativo de justicia.

Dentro de este interés por cuantificar los logros, merece especial atención el recurso que utilizan algunas ONGD de traducir en resultados tangibles las donaciones o cuotas de socios: "En Siria, con $10 €$ al mes durante 6 meses[,] 1 familia recibirá ropa de abrigo de invierno para protegerse del frío" (OI, 2013c). Sonrisas de Bombay (2013c) explica que, por $10 €$ al mes durante un año, "3 personas beneficiarias del proyecto 'Campos de salud oftalmológicos' podrán ser operadas de cataratas[,] recuperando su visión y mejorando su calidad de vida”. Esta 


\section{DISERTACIONES}

ESTUDIOS

Anuario electrónico de estudios en Comunicación Social

ISSN: $1856-9536$

Doi: dx.doi.org/10.12804/revistas.urosario.edu.co/disertaciones/a.4910

Volumen 10, Número 1/ Enero-junio 2017

Versión PDF para imprimir desde

http://revistas.urosario.edu.co/index.php/disertaciones

organización anima así a apoyar económicamente a la entidad: "Por tan sólo $0,33 €$ al día ya puedes ser socia o socio colaborador".

Aunque sin renunciar a los ingresos que puedan generar las donaciones o las cuotas de socios, la visión de las ONGD más claramente ubicadas en el marco alternativo sobre la tarea de conseguir fondos es muy diferente. Acsur-Las Segovias sitúa esa labor en un segundo plano, al subrayar que la herramienta de transformación no es la recaudación de dinero, sino la movilización de la ciudadanía y el activismo político. Por su parte, Setem le da la vuelta al discurso tradicional de las ONGD y explica que, con $30 €$ al año, se colabora para que un activista participe en la Junta de Accionistas del Banco Santander para denunciar los impactos negativos de las inversiones de la entidad financiera. VSF-JAG (2013b) usa un recurso similar y equipara las aportaciones puntuales o las cuotas anuales de socios con inversiones a un supuesto fondo de inversión cuyo objetivo es acabar con "la especulación alimentaria", pero hace la traducción del impacto real que tendría ese objetivo, al asegurar que así se evitaría que "40 millones de personas sean empujadas al hambre a causa de una nueva crisis de los precios de los alimentos".

Además del interés por cuantificar su labor, las organizaciones en las que el marco hegemónico caritativo tiene un peso importante se distinguen por otra característica: el afán por demostrar cualificación técnica para desempeñar su trabajo. ACH (2013) alude a su "conocimiento y experiencia en nutrición, seguridad alimentaria, agua y saneamiento, salud e incidencia política", mientras BdR destaca que sus técnicos se encargan tanto de la planificación como del seguimiento y de la evaluación de sus proyectos y SdB (2013d) explica que aplica "una metodología y unos estándares de calidad en sus materiales pedagógicos". Algunas ONGD refuerzan esta presentación propia como entidades competentes mediante la exhibición de acreditaciones externas. Es el caso de CRC, que resalta que su sistema de gestión de calidad sigue los criterios de la Asociación Española de Normalización y Certificación (Aenor), responsable de adaptar las normativas internacionales ISO al ámbito estatal. Además, CRC (2013) subraya que ha obtenido el certificado ONG Benchmarking, "que acredita la transparencia y la responsabilidad de sus proyectos y actuaciones".

Una carencia generalizada en los sitios web de las ONGD es la escasa visibilidad de los actores del Sur y la falta de información de calidad sobre la situación de esos países. En contraposición, la propia ONGD se sitúa en el centro del discurso. Un ejemplo se encuentra en la explicación de los proyectos de cooperación. Las entidades hablan de su trabajo (explicación del proyecto, entidades financiadoras, población asistida, etc.), mientras el de las contrapartes queda invisibilizado y, en general, como mucho, solo se puede encontrar el nombre de la entidad con un enlace a su sitio web (es el caso de una organización con un discurso claramente ubicado en el marco alternativo como Acsur-Las Segovias). Mucho más difícil todavía es leer testimonios directos de las personas de los países en donde se desarrollan los proyectos (en el sitio web de Ol sí se pueden ver algunos).

Asociadas con la invisibilidad del Sur están las casi inexistentes explicaciones sobre las causas estructurales de la pobreza y la desigualdad en el mundo. La falta de una información crítica sobre los motivos últimos de la injusticia social es característica, en especial, de las organizaciones más grandes o más orientadas al marco hegemónico caritativo. Un buen ejemplo lo ofrece $\mathrm{ACH}$; aunque en su web se habla de las causas del hambre, no se denuncia la existencia de un sistema global injusto ni la responsabilidad del Norte en esa situación.

Una entidad situada dentro del marco alternativo, VSF-JAG, ofrece una visión mucho más crítica sobre el mismo problema del hambre. Esta ONGD expone que el actual modelo de producción, comercialización y consumo de alimentos es la principal causa de hambre y pobreza en el mundo. Denuncia, además, las prácticas de grandes empre- 
sas y Gobiernos, como el acaparamiento de tierras o la especulación alimentaria. ODG es otra de las organizaciones que escapa a la norma general e incluye en su sitio web abundante información sobre la deuda externa.

Algunas de las entidades más cercanas al marco de transformación muestran incoherencias entre el discurso que exhiben y el vocabulario con el que lo acompañan. ACPP (2013), por ejemplo, se desmarca "del asistencialismo y de la instrumentalización de las ayudas", pero no duda en hablar de "beneficiarios" de sus proyectos y de "países en vías de desarrollo". Otras organizaciones, sin embargo, muestran un especial cuidado con el lenguaje. Es el caso de Proide. (2013), que habla de "países empobrecidos" y "países del Sur", al tiempo que evita el verbo "ayudar", que sustituye por "cooperar" o "colaborar", igual que OI (2013a) lo hace por "apoyar" o "dar respaldo". Sin embargo, el cuidado uso del vocabulario que muestra esta última organización en sus textos queda ensombrecido con el llamamiento destacado a hacer una aportación económica ("Haz un donativo") que figura en la parte superior derecha de todas sus páginas. Setem. (2013b), por su parte, además de utilizar la expresión "países empobrecidos", va un paso más allá, al emplear términos que sirven para denunciar la construcción de una determinada visión del mundo que facilita el lenguaje como "sociedades denominadas desarrolladas" o "países denominados emergentes". En general, las organizaciones más cercanas al marco hegemónico utilizan un vocabulario que contribuye a reforzar la visión asistencial de la solidaridad. En el sitio web de BdR. (2013). se pueden encontrar expresiones como "países y colectivos necesitados", "Tercer Mundo", "países en vías de desarrollo", "beneficiarios" o "donantes". Las fotografías de los sitios web están más cuidadas. Por ejemplo, OI se preocupa por que las personas que aparezcan en sus imágenes (sobre todo, mujeres) estén ejecutando alguna actividad y no recibiendo ayuda. En el lado contrario se pueden encontrar las organizaciones más cercanas al marco hegemónico, como ACH, en cuya web abundan las fotografías de personas de los países empobrecidos (en especial, de raza negra) cuando reciben atención o ayuda o participan en talleres de formación.

\section{Discusión}

El análisis de los sitios web de las ONGD catalanas muestra un balance con luces y sombras. Por una parte, la mayoría de las entidades ofrecen un discurso más cercano al marco alternativo que busca la transformación social, pero, por otra, el marco hegemónico caritativo continúa teniendo un peso considerable, en particular en las organizaciones de mayores dimensiones y con mayor visibilidad (como ACH, CRC u OI). Ese balance mixto, sin embargo, supone una actualización con respecto a estudios anteriores de la comunicación de las ONGD españolas centrados en el ámbito de la publicidad como los de Nos-Aldás (2007) y Pagola (2009) o el de Erro Sala y Ventura (2002) sobre las ONGD vascas, que constataban el dominio de un enfoque instrumental de la comunicación orientado a la satisfacción de objetivos corporativos, de consolidación de marca y recaudación de fondos. En este sentido, se puede hablar de una lenta erosión del marco hegemónico asistencial.

No obstante, todavía queda mucho camino por recorrer, ya que el enfoque caritativo ofrece una fuerte resistencia en un contexto de crisis en el que las restricciones presupuestarias dificultan el logro de financiación (Reuters, $2016)^{3}$. La presión por obtener recursos a corto plazo lleva a las organizaciones, sobre todo a las de mayores dimen-

3 Entre 2010 y 2014, la ayuda pública al desarrollo de España disminuyó un 68 \%, según los datos de la Organización para la Cooperación y el Desarrollo Económico (OCDE). 
siones, a situar la captación de fondos como elemento central de su estrategia de comunicación y a adoptar técnicas de mercadotecnia que actúan en contra de los objetivos de transformación social a largo plazo (Erro Sala, 2002; 2010; Martínez Osés, 2011; Nos-Aldás, 2007; 2010; Sogge, 1998). Mensajes como los ya referidos de Ol o Sonrisas de Bombay que, para incentivar las donaciones, convierten en logros tangibles (ya sea ropa de abrigo o personas que recibirán atención médica) las cantidades recibidas, o los llamamientos de SdB para hacerse socio de la entidad desde "sólo" 0,33 € al día, despojan la solidaridad de cualquier connotación de compromiso con un orden social más justo y transmiten la idea de una "solidaridad de salón" (Ballesteros García, 2002, p. 89), que crea la ilusión de que se pueden transformar las realidades injustas sin esfuerzo con productos de consumo asequibles a cualquier bolsillo. Como apunta Erro Sala (2002), no se pueden separar medios de fines y es posible pedir dinero al tiempo que se moviliza a la sociedad en torno al problema de la pobreza y se crea una cultura de la solidaridad o, como señala Nos-Aldás (2007; 2010), los mensajes orientados a la captación de fondos deben tener "eficiencia cultural" y no ir en contra de los mensajes de transformación social. Las fórmulas que utiliza Setem irían en esa línea.

Además, determinadas ONGD (sobre todo las más próximas al marco hegemónico) utilizan diferentes estrategias para crearse una imagen positiva en el competitivo "supermercado de la solidaridad" (Ballesteros García, 2002, p. 89) que les facilite la obtención de donaciones y financiación: se sitúan como protagonistas del relato que elaboran, se presentan como actores altamente cualificados para solucionar los problemas de las poblaciones y los países empobrecidos y muestran gran interés en cuantificar sus logros (personas atendidas, proyectos ejecutados, etc.).

Estas estrategias apuntalan, de nuevo, el marco asistencial: se refuerzan los roles tradicionales de un Norte activo y cualificado técnicamente frente a un Sur pasivo y necesitado de ayuda, el foco de interés se sitúa en las propias ONG y no en las poblaciones empobrecidas y se privilegian los objetivos cuantificables a corto plazo sobre los cambios estructurales. A la inversa, el compromiso de las organizaciones más cercanas al marco alternativo con un proceso de transformación a largo plazo que permita un sistema más justo incide en que no se enfoquen tanto en logros objetivables inmediatos impulsados por la propia entidad, sino en los avances que se puedan conseguir gracias a su labor de denuncia y a la progresiva sensibilización de la ciudadanía.

En general, las organizaciones se caracterizan por su hibridismo, de forma que son visibles tanto elementos del marco hegemónico de corte caritativo como del alternativo de carácter transformador. En el discurso que utilizan para presentarse dominan los rasgos de este último: las apelaciones a la justicia social, por ejemplo, son abundantes en un buen número de entidades. El problema aparece cuando estos textos se confrontan con los proyectos que las ONGD desarrollan. No se trata de que todas las organizaciones orienten sus esfuerzos a tareas de sensibilización o incidencia política (como hacen Setem o VSF-JAG) - aunque sí sería deseable que este tipo de actividades tuviera un mayor peso en sus proyectos-, sino de que "todas aborden el trabajo desde un enfoque que asuma que el desarrollo es fundamentalmente una categoría política vinculada con el enfoque basado en derechos y el cambio estructural" (Plataforma 2015 y Más, 2011, p. 79), exigencia que está recogida en los códigos éticos de las ONGD catalanas ${ }^{4}$

4 Lafede.cat-Organizaciones para la Justicia Global tiene un código ético elaborado a partir de los procedentes de la FCONGD y de la Federación Catalana de ONG para los Derechos Humanos. 


\section{DISERTACIONES}

ESTUDIOS

Anuario electrónico de estudios en Comunicación Social

ISSN: $1856-9536$

Doi: dx.doi.org/10.12804/revistas.urosario.edu.co/disertaciones/a.4910

Volumen 10, Número 1 / Enero-junio 2017

Versión PDF para imprimir desde

http://revistas.urosario.edu.co/index.php/disertaciones

(FCONGD, 2007) y españolas (Coordinadora de ONG para el Desarrollo-España, 2014) 5 . En este sentido, la mayor parte del trabajo de las ONGD catalanas en los países empobrecidos, sobre todo el de las grandes organizaciones, sigue adoleciendo de una orientación básicamente asistencial. En el lado contrario se podría citar el enfoque con el que AlterNativa aborda sus proyectos.

Una carencia generalizada que presentan las ONGD en sus sitios web es la falta de explicaciones profundas sobre las causas de la injusticia social y la pobreza en el mundo y la responsabilidad de los países y las organizaciones del Norte en esa situación, así como la ausencia de propuestas concretas para avanzar hacia la transformación social a largo plazo - las entidades que sí incluyen este tipo de información son Acsur-Las Segovias, Setem, VSF-JAG y ODG-. Estas insuficiencias discursivas pueden atribuirse, al menos parcialmente, a "un alto grado de cautela respecto a la dimensión política" (Martínez Osés, 2011, p. 18). De esta forma, las organizaciones prefieren no implicarse en explicaciones que podrían afectar su pretendida neutralidad y perjudicar su posición frente a posibles financiadores.

Frente a esta situación, se plantea una vuelta de las organizaciones a sus orígenes y su repolitización (Ruiz-Giménez, 2013). Esta propuesta, expresada de forma genérica, merece una precisión, ya que algunas organizaciones no han perdido ese espíritu primigenio de lucha por la transformación social y otras nacieron con una voluntad básicamente asistencial (Plataforma 2015 y Más, 2011). Resulta mucho más preciso situar a las ONGD en un contínuum entre dos extremos: las organizaciones de conflicto y las gestoras (Sampedro, Jerez Novara y López Rey, 2002). Tener en cuenta la naturaleza y las condiciones en las que surgió cualquier ONGD es imprescindible para evaluar su actuación, ya que es mucho más complicado cambiar unas dinámicas de trabajo enraizadas desde hace años o decenios, que recuperar la filosofía inicial. Un buen ejemplo entre las organizaciones analizadas lo ofrece Cruz Roja, institución creada a mediados del siglo XIX con el objetivo de atender a heridos de guerra. El carácter asistencial de esta entidad forma parte de su identidad más profunda, por lo que introducir cambios en su visión de la solidaridad no es sencillo. De todas formas, sí se pueden apreciar elementos de transformación. Por ejemplo, en la página de formación de su web, CRC señala que la ampliación de líneas de actuación ha creado nuevas necesidades en campos como la paz y los derechos humanos.

La preocupación por evitar los mensajes que presentan una visión simplificada y distorsionada de la realidad, con un Sur en situación de emergencia y necesitado de ayuda urgente, estuvo en el origen del primer código de conducta de las ONG europeas (Comité de enlace de las ONG europeas ante la Comisión Europea, 1989), tomado como referencia para las regulaciones posteriores en España. Aunque el discurso que utilizan las organizaciones para explicar su actividad sigue presentando evidentes carencias como las ya señaladas, sí hay mejoras que vuelven a apuntar a un paulatino quiebre del marco caritativo hegemónico. Las imágenes con elevada carga emocional para incitar a las donaciones o que refuerzan los estereotipos del Sur pasivo y necesitado de ayuda se pueden considerar una excepción en los sitios web analizados. En el uso del vocabulario también se observan algunos avances, pero en este aspecto todavía queda mucho camino por recorrer. Expresiones como "países en vías de desarrollo" o "beneficiarios", que favorecen una visión del mundo desde la perspectiva occidental y refuerzan el marco asistencial, siguen teniendo una notable vigencia. El hecho de que sean utilizadas, incluso, por organiza-

5 El Código de conducta de la Coordinadora de ONGD-España fue aprobado en 1998 y ha sufrido diversas modificaciones hasta su última versión de 2014. 
ciones que mantienen un discurso cercano al marco alternativo es una muestra más del proceso de cambio que afrontan las organizaciones: hay una reflexión en marcha, sí, pero aún necesita una mayor maduración. Incoherencias como las del vocabulario utilizado son tanto indicio como consecuencia de la transformación en curso.

El proceso de reflexión emprendido por las ONGD que está minando de forma progresiva el marco hegemónico tiene como una de sus principales impulsoras la labor realizada por las coordinadoras de ONGD estatales (Coordinadora de ONG para el Desarrollo-España) y, en el caso concreto que se analiza en este artículo, catalanas. Estas coordinadoras han actuado como espacios de debate y autocrítica y han servido para orientar la actuación de sus entidades afiliadas. Es significativo el nuevo nombre que adoptó la FCONG en septiembre de 2014, cuando pasó a llamarse Lafede.cat-Organizaciones para la Justicia Global. La nueva denominación es un claro ejemplo del agrietamiento progresivo que está sufriendo el marco hegemónico asistencial a favor del marco alternativo de transformación, proceso evidente en algunas organizaciones. Por ejemplo, Sonrisas de Bombay (2013a) hace referencia en su web a su Plan Estratégico 2011-2015 y asegura que, si bien su objetivo inicial era "mejorar la vida a algunas personas concretas", poco a poco han ido evolucionando hacia un proyecto que busca promover "una transformación hacia una sociedad más justa", lo que se ha plasmado en la introducción de "cambios estructurales y objetivos integrales" en sus proyectos. En este sentido, existen pocas certezas sobre el tipo de organizaciones más inclinadas a romper con el marco hegemónico asistencial. En cualquier caso, una entidad que tenga claros sus principios y hacia dónde quiere avanzar tendrá mucho terreno ganado porque, como asegura Sogge (1998), el desafío más importante que tienen las organizaciones es el de su identidad.

\section{Conclusiones}

El análisis de los sitios web de las ONGD de Cataluña demuestra el progresivo agrietamiento del marco hegemónico basado en un discurso caritativo que tiende a consolidar los estereotipos Norte-Sur y desincentiva la transformación social. El marco alternativo orientado al cambio social prevalece, en mayor o menor medida, en diez de las diecisiete organizaciones analizadas, aunque cabe reconocer que las mayores y, por lo tanto, con más visibilidad, todavía muestran su cercanía al marco asistencial, lo que dificulta su erosión. De todas formas, no se puede establecer una relación directa entre dimensión y proximidad a los planteamientos caritativos tradicionales, ya que estos también aparecen en organizaciones de un tamaño pequeño o medio.

Sin embargo, los cambios no dejan de producirse, incluso en las entidades más grandes. Oxfam-Intermón es un buen ejemplo. Un dato concreto permite ilustrar esta evolución: la pestaña con el texto "Haz un donativo", que dominaba todas las páginas del sitio web de OI en el momento del análisis, ha sido sustituida por otra con la leyenda "Hazte socio/a". Pese a que el apunte puede parecer nimio, refleja a la perfección el proceso de cambio en el que muchas organizaciones están inmersas.

Las mejoras en algunas cuestiones que constata el análisis (por ejemplo, en el tipo de imágenes difundidas) no pueden ocultar carencias generalizadas como la invisibilidad de los actores del Sur y la falta de explicaciones profundas sobre las causas estructurales de la injusticia social que domina el planeta. Las ONGD deberían afrontar un proceso interno de reflexión que les permitiera desarrollar un discurso y unas prácticas coherentes con el objetivo de transformación social que, de acuerdo con los códigos éticos del sector, las define como organizaciones. Solo así la fotografía que se pueda obtener en un análisis futuro resultará más nítida que la lograda en este estudio. 


\section{DISERTACIONES}

ESTUDIOS

Anuario electrónico de estudios en Comunicación Social

ISSN: 1856-9536

Doi: dx.doi.org/10.12804/revistas.urosario.edu.co/disertaciones/a.4910

Volumen 10, Número 1 / Enero-junio 2017

Versión PDF para imprimir desde

http://revistas.urosario.edu.co/index.php/disertaciones

\section{Agradecimientos y financiación}

Este trabajo forma parte de dos proyectos de investigación: el proyecto de la Unión Europea DevReporter, "Red de periodistas y profesionales de la comunicación para la cooperación y el desarrollo" (proyecto número DCI-NSAPVD/2012/279-805), coordinado por la Federación Catalana de ONGD (el artículo es resultado del contrato de investigación suscrito entre la Federación Catalana de ONGD y la Universitat Jaume I de Castellón en el marco del citado proyecto europeo) y el proyecto "Testimonio ético y comunicación para el cambio: análisis de modos de re-significación de la figura de la víctima y de re-situación de los agentes sociales” (P1·1B2015-21 del Programa de Promoción de la Investigación de la UJI).

\section{Referencias}

1. ACH. (2013). Quiénes somos. Recuperado de http://www.accioncontraelhambre.org/quienes_somos.php

2. ACPP. (2013). Misión, visión y valores. Recuperado de http://www.acpp.com/about-us/mision-vision-y-valores/mision-vision-y-valores-2/

3. Acsur-Las Segovias. (2013). Quiénes somos. Recuperado de http://acsur.org/-QUIENES-SOMOS-

4. Ballesteros García, C. (2002). Supermercados de la solidaridad. En L. Nieto (coord.), La ética de las ONGD y la lógica mercantil (pp. 89-134). Barcelona: Icaria.

5. BdR (2013). Presentació. Recuperado de http://www.bancderecursos.org/index.php/ca/l-entitat/presentacio

6. Centre Tricontinental. (1998). Les ONG: instruments du néo-libéralisme ou alternatives populaires? París: L'Harmattan.

7. Centro de Investigaciones Sociológicas. (2015). Barómetro de abril de 2015. Recuperado de http://www. cis.es/cis/export/sites/default/_Archivos/Marginales/3080_3099/3080/es3080mar.pdf

8. Clark, J. (1991). Democratizing Development: The Role of Voluntary Organizations. Londres: Earthscan Publications.

9. Comité de Enlace de las ONG europeas ante la Comisión Europea. (1989). Código de conducta. Recuperado de http://cederul.unizar.es/docs/iniciacion_cooperacion/segunda.e.peyroln.cdigoconductaii.pdf

10. Coordinadora de ONG para el Desarrollo-España. (2010). Así nos ven: ¿Qué sabemos y cómo valoramos a las ONGD? Recuperado de http://coordinadoraongd.org/old/980/original/20100706_130710_Asi_nos_ ven_web_low.pdf

11. Coordinadora de ONG para el Desarrollo-España (2014). Código de conducta de las ONG de desarrollo. Recuperado de http://coordinadoraongd.org/wp-content/uploads/2016/01/Codigo_Conducta.pdf

12. CRC. (2013). Servicios. Recuperado de http://www.creuroja.org/AP/CM/1727P22/Serveis.aspx

13. Darnton, A. y Kirk, M. (2011). Finding Frames: New Ways to Engage the UK Public in Global Poverty. Londres: Oxfam, Department for International Development (DFID).

14. Edualter. (2013). EduAlter. Recuperado de http://www.edualter.org/index.htm

15. Erro Sala, J. (2002). Comunicación, desarrollo y ONGD. Bilbao: Hegoa. 


\section{DISERTACIONES}

ESTUDIOS

Anuario electrónico de estudios en Comunicación Social

ISSN: 1856-9536

Doi: dx.doi.org/10.12804/revistas.urosario.edu.co/disertaciones/a.4910

Volumen 10, Número 1 / Enero-junio 2017

Versión PDF para imprimir desde

http://revistas.urosario.edu.co/index.php/disertaciones

16. Erro Sala, J. (2010). Comunicación, cooperación internacional para el desarrollo y ONGD: Un modelo de trabajo desde la educación y la cultura. En T. Burgui y J. Erro Sala (coords.), Comunicando para la solidaridad y la cooperación: cómo salir de la encrucijada (pp. 137-176). Pamplona: Foro Comunicación, Educación y Ciudadanía.

17. Erro Sala, J. y Ventura, J. (2002). El trabajo de comunicación de las ONGD en el País Vasco. Bilbao: Hegoa.

18. FCONGD. (2007). Codi ètic i de conducta per a les ONGD federades. Recuperado de http://www.urv.cat/ media/upload/arxius/URV_Solidaria/Info_Documental/codietic2007.pdf

19. Giró, X., Farrera, L. y Giró, V. (2015). La cooperació i la solidaritat internacional segons els mèdia a Catalunya: percepció i discurs reflectit. Informe DevReporter. Recuperado de http://devreporternetwork.eu/ wp-content/uploads/2013/10/Estudi_Mitjans_DR.pdf

20. Gómez Gil, C. (2004). Las ONG en la globalización: estrategias, cambios y transformaciones de las ONG en la sociedad global. Barcelona: Icaria.

21. Gómez Gil, C. (2005). Las ONG en España: de la apariencia a la realidad. Madrid: Los libros de la catarata.

22. Gómez Gil, C. (2013). ONG en crisis y crisis en las ONG: un fin de ciclo en el oenegeísmo en España. Temas para el Debate, 221, 23-25.

23. Hulme, D. y Edwards, M. (eds.) (1997). NGOs, States and Donors: Too Close for Comfort? Nueva York: St. Martin's Press.

24. Iranzo, A. y Farné, A. (2014). Herramientas de comunicación para el tercer sector: el uso de las redes sociales por las ONGD catalanas. Commons, Revista de Comunicación y Ciudadanía Digital, 3 (2), 29-50.

25. Lakoff, G. (2004). Don't Think of an Elephant: Know Your Values and Frame the Debate. White River Junction: Chelsea Green.

26. Llistar, D. (2009). Anticooperación. Barcelona: Icaria.

27. Marí-Sáez. V. M. y Ceballos-Castro, G. (2015). Análisis bibliométrico sobre "comunicación, desarrollo y cambio social” en las diez primeras revistas de Comunicación de España. Cuadernos.info, 37, 201-212. DOI: $10.7764 / \mathrm{cdi} .37 .828$

28. Martínez Osés, P. J. (2011). Redefinición del papel de las ONGD: hacia una mirada más política. En I. Martínez (coord.), Renovando el papel de las ONGD: hacia la transformación social (pp. 13-24). Madrid: Editorial 2015 y Más. Recuperado de http://www.2015ymas.org/IMG/pdf/Renovando_el_papel.pdf

29. MMC. (2013a). Quiénes somos. Recuperado de http://www.medicusmundi.es/index.php/catalunya/la_nostra_associacio/qui_som

30. MMC. (2013b). Nuestra misión. Recuperado de http://www.medicusmundi.es/index.php/catalunya/la nostra_associacio/la_nostra_missio

31. Nieto, L. (coord.) (2002). La ética de las ONGD y la lógica mercantil. Barcelona: Icaria

32. Nos-Aldás, E. (2007). Lenguaje publicitario y discursos solidarios: eficacia publicitaria ¿eficacia cultural? Barcelona: Icaria.

33. Nos-Aldás, E. (2010). Comunicación, cultura y educación para la solidaridad y el desarrollo: un análisis desde el discurso. En T. Burgui y J. Erro Sala (coords.), Comunicando para la solidaridad y la cooperación: cómo salir de la encrucijada (pp. 113-134). Pamplona: Foro Comunicación, Educación y Ciudadanía. 


\section{DISERTACIONES}

ESTUDIOS

Anuario electrónico de estudios en Comunicación Social

ISSN: 1856-9536

Doi: dx.doi.org/10.12804/revistas.urosario.edu.co/disertaciones/a.4910

Volumen 10, Número 1 / Enero-junio 2017

Versión PDF para imprimir desde

http://revistas.urosario.edu.co/index.php/disertaciones

34. Nos-Aldás, E., Iranzo A. y Farné, A. (2012). La eficacia cultural de la comunicación de las ONGD: los discursos de los movimientos sociales actuales como revisión. CIC Cuadernos de Información y Comunicación, 17, 209-237.

35. Nos-Aldás, E. y Santolino, M. (2015). La investigación en comunicación y cooperación en los nuevos escenarios de movilización social: ONGD, objetivos de justicia social y eficacia cultural. Revista de la Asociación Española de Investigación de la Comunicación, 2(4), 1-7.

36. ODG. (2013). Qué hacemos. Recuperado de http://www.odg.cat/...84\&id_noticia=\&id_agenda=\&publicacions=\&id_publicacions=\&categorialink=\&id_butlleti=\&any_but=\&id_nota=\&id=

37. OI. (2013a). Presentación. Recuperado de http://www.oxfamintermon.org/ca/qui-som/presentacio

38. OI. (2013b). Misión, visión y valores. Recuperado de http://www.oxfamintermon.org/ca/qui-som/presentacio/missio-visio-valors

39. OI. (2013c). Fondo de emergencias. Recuperado de http://www.oxfamintermon.org/ca/accion-humanitaria/emergencia/fons-demergencies

40. Pagola, J. (2009). Comunicación para el desarrollo: la responsabilidad en la publicidad de las ONGD. San Sebastián: Diputación Foral de Guipúzcoa.

41. Pinazo, D. y Nos-Aldás, E. (2016). Developing Moral Sensitivity through Protest Scenarios in International NGDOs' Communication. Communication Research, 43 (1), 25-48. DOI: 10.1177/0093650213490721

42. Plataforma 2015 y Más. (2001). Renovando nuestro papel hacia la transformación social. En En I. Martínez (coord.), Renovando el papel de las ONGD: hacia la transformación social (pp. 69-89). Madrid: Editorial 2015 y Más. Recuperado de http://www.2015ymas.org/IMG/pdf/Renovando_el_papel.pdf

43. Proide (2013). Qui Som? Recuperado de http://www.fundacioproide.org/

44. Reimann, K. (2006). A View from the Top: International Politics, Norms and the Worldwide Growth of NGOs. International Studies Quarterly, 50, 45-67.

45. Reuters. (4 de marzo de 2016). La OCDE pide a España que revierta la caída de la ayuda al desarrollo. Recuperado de http://es.reuters.com/article/entertainmentNews/idESKCNOW61B0

46. Rizzardini, M. (2002). La producción de conocimiento y comunicación de las ONGD: entre la ideología dominante y un imaginario social alternativo. En M. Revilla Blanco (ed.), Las ONG y la política (pp. 286345). Madrid: Istmo.

47. Ruiz-Giménez, M. (2013). ONGD: volviendo a los orígenes para construir alternativas. Crítica, 983, 48-53.

48. Sampedro, V., Jerez Novara, A. y López Rey, J. (2002). ONG, medios de comunicación y visibilidad pública. La ciudadanía ante la mediatización de los mensajes sociales. En M. Revilla Blanco (Ed.), Las ONG y la política (pp. 251-285). Madrid: Istmo.

49. Santolino, M. (2010). Recuperando la esencia: las ONGD como agentes de comunicación para el cambio social. En T. Burgui y J. Erro Sala (coords.), Comunicando para la solidaridad y la cooperación: cómo salir de la encrucijada (pp. 221-256). Pamplona: Foro Comunicación, Educación y Ciudadanía.

50. Serrano Oñate, M. (2002). Las ONGD en la encrucijada: del Estado de bienestar a la franquicia del Estado. En M. Revilla Blanco (Ed.), Las ONG y la política (pp. 66-94). Madrid: Istmo.

51. Setem. (2013). Sé el cambio. Recuperado de http://www.setem.org/site/cat/catalunya/sigues-el-canvi

52. Setem. (2013). Objectius. Recuperado de http://www.setem.org/site/cat/calalunya/objectius 


\section{DISERTACIONES}

ESTUDIOS

53. Sogge, D. (1998). Escenarios y elecciones. En Autor (ed.), Compasión y cálculo: un análisis crítico de la cooperación no gubernamental al desarrollo (pp. 21-48). Barcelona: Icaria.

54. Sogge, D. y Zadek, S. (1998). ¿"Leyes” del mercado? En D. Sogge (ed.), Compasión y cálculo: un análisis crítico de la cooperación no gubernamental al desarrollo (pp. 103-139). Barcelona: Icaria.

55. Sonrisas de Bombay. (2013a). Plan estratégico. Recuperado de https://www.sonrisasdebombay.org/sonrisasdebombay/es/quienes-somos/plan-estrategico.html

56. Sonrisas de Bombay. (2013b). Sensibilización. Recuperado de https://www.sonrisasdebombay.org/sonrisasdebombay/es/que-hacemos/sensibilizacion.html

57. Sonrisas de Bombay. (2013c). Hacerte socio. Recuperado de https://www.sonrisasdebombay.org/sonrisasdebombay/es/que-puedes-hacer-tu/hacerte-socio.html

58. Sonrisas de Bombay. (2013d). Educación. Recuperado de https://www.sonrisasdebombay.org/sonrisasdebombay/es/que-hacemos/educacion.htm

59. Tufte, T. (2015). Comunicación para el cambio social. Barcelona: Icaria.

60. VSF-JAG. (2013a). Alternativas. Recuperado de http://vsf.org.es/alternativas

61. VSF-JAG. (2013b). Fondo inversión VSF. Recuperado de http://bancabajocontrol.vsf.org.es/fondo-inversion-vsf 